\title{
Review: anticonvulsant drugs relieve chronic but not acute pain
}

\author{
Wiffen P, Collins S, McQuay H, et al. Anticonvulsant drugs for acute and chronic pain. Cochrane Database Syst Rev \\ 2000;(3):CD001133 (latest version 23 May 2000).

\section{QUESTION: In patients with acute or chronic pain, how effective are anticonvulsant drugs in providing pain relief?}

\section{Data sources}

Studies were identified by searching Medline (1966 to July 1999), EMBASE/Excerpta Medica (1994 to July 1999), SIGLE (1980 to July 1999), the Cochrane Library, and the reference lists of relevant studies and by contacting investigators in the field. 40 medical journals were also handsearched for the period between 1950 and 1990.

\section{Study selection}

Studies were selected if they were randomised controlled trials that investigated the analgesic effects of anticonvulsant drugs in adults and if pain assessment was an outcome measure. Studies of migraine or headache were excluded.

\section{Data extraction}

Data were extracted on number of patients, anticonvulsant drug and dosing regimen, pain condition, study design (placebo or active control), study duration and follow up, analgesic outcome measures and results, and withdrawals and adverse effects.

\section{Main results}

23 trials of 6 anticonvulsant drugs were included: carbamazepine (12 trials), phenytoin (6 trials), sodium valproate (2 trials), gabapentin (2 trials), clonazepam (1 trial), and lamotrigine ( 1 trial). 2 trials studied acute pain: 1 placebo controlled trial showed no effect for intravenous sodium valproate, and 1 trial of acute herpes zoster showed carbamazepine to be less effective than prednisolone in relieving pain and promoting skin healing. Other trials studied chronic pain: carbamazepine was effective in 3 of 4 trials in trigeminal neuralgia, and lamotrigine was no more effective than placebo in 1 trial (table). Carbamazepine, phenytoin, and gabapentin were more effective than placebo in relieving the pain of diabetic neuropathy (table). One trial showed gabapentin was more effective than placebo in relieving postherpetic neuralgia (table). Carbamazepine, gabapentin, and phenytoin all caused such minor side effects as drowsiness, dizziness, constipation, nausea, and ataxia (numbers needed to harm [NNHs] ranged from 3 to 4). The NNHs for major harm were not statistically significant for any drug.

\section{Conclusions}

In patients with chronic pain, anticonvulsant drugs provide pain relief. Anticonvulsant drugs have not shown convincing evidence of efficacy in the treatment of acute pain states.

Anticonvulsant drugs v placebo for pain relief in adults with chronic pain*

\begin{tabular}{|c|c|c|c|c|c|}
\hline Pain condition & $\begin{array}{l}\text { Number of } \\
\text { trials }\end{array}$ & \multicolumn{2}{|c|}{ Weighted event rates } & RBI $(95 \% \mathrm{Cl})$ & NNT (Cl) \\
\hline Diabetic neuropathy & 3 & $72 \%$ & $38 \%$ & $83 \%(30$ to 159$)$ & 3 (3 to 5$)$ \\
\hline Post-herpetic neuralgia† & 1 & $43 \%$ & $12 \%$ & $257 \%$ (109 to 511$)$ & 4 (3 to 5$)$ \\
\hline
\end{tabular}

${ }^{*}$ Random effects model used for all analyses. Follow up ranged from 5 weeks to 46 months. Abbreviations defined in glossary; RBI, NNT, and $\mathrm{Cl}$ calculated from data in article.

†Event rates not weighted.

Source of funding Marie Curie Cancer Care; Oxford Regional Health Authority; Pain Research Funds (UK).

For correspondence: Mr P Wiffen, Cochrane Pain, Palliative and Supportive Care CRG, Pain Research Unit, Churchill Hospital, Old Road, Oxford OX3 7LJ, UK. Fax $+44(0) 1865$ 225400 .

\section{COMMENTARY}

The general approach to chronic pain management is complex. It should (although it often does not) involve non-pharmacological and behavioural methods in treatment, usually in an interdisciplinary setting. In most chronic pain states, anticonvulsant drugs are used and most are useful in the role of adjuvant treatment. With few exceptions (divalproex for migraine and carbamazepine for trigeminal neuralgia), they do not solve the problem of pain management by themselves.

The pathophysiology of chronic pain is heterogeneous, and anticonvulsants do not have a single mechanism of action. Evaluating the combined effects of single anticonvulsants in different pain conditions or evaluating the combined effects of different anticonvulsants in a single pain condition may obscure clinically important activity of specific drugs in specific pain conditions.

In the meta-analysis by Wiffen $e t$ al, migraine studies were specifically excluded. Anecdotal evidence supports the use of intravenous depakene as abortive treatment for the acute pain of migraine. Divalproex sodium has documented efficacy for alleviating the chronic pain of recurrent migraine. The rigorous criteria for study inclusion in this analysis excluded potentially effective older drugs that have not been properly tested. Further rigorous studies need to be done with older drugs.

Of clinical interest and with implications for clinical practice is the caution against the often taught idea that a positive response to carbamazepine is "diagnostic" for trigeminal neuralgia. The review by Wiffen $e t$ al points out that only $70 \%$ of patients have substantial pain relief with carbamazepine.

In certain pain conditions, anticonvulsant drugs provide pain relief. Anticonvulsant drugs have not been convincingly shown to relieve acute pain, but this remains under study. 